\title{
In search of the fibrotic epithelial cell: opportunities for a collaborative network
}

\author{
Gisli Jenkins, ${ }_{1}^{1}$ Andrew Blanchard, ${ }^{2}$ Zea Borok ${ }^{3}$ Peter Bradding, ${ }^{4}$ Carsten Ehrhardt, ${ }^{5}$ \\ Andrew Fisher, ${ }^{6}$ Nik Hirani, ${ }^{7}$ Simon Johnson, ${ }^{1}$ Melanie Königshoff, ${ }^{8}$ Toby M Maher, ${ }^{9}, 10$ \\ Ann Millar, ${ }^{11}$ Helen Parfrey, ${ }^{12}$ Chris Scotton, ${ }^{10}$ Terry Tetley, ${ }^{13}$ David Thickett, ${ }^{14}$ \\ Paul Wolters, ${ }^{15}$ on behalf of the contributors to the ECIPF workshop
}

For numbered affiliations see end of article.

\section{Correspondence to}

Gisli Jenkins, Respiratory Biomedical Research Unit, Clinical Sciences Building, City Hospital Campus, University of Nottingham, Hucknall Road, Nottingham NG5 1PB, UK; gisli.jenkins@nottingham.ac.uk

Proceedings of the First International Workshop on Epithelial Cells in Idiopathic Pulmonary Fibrosis (ECIPF), 15 October 2010, Nottingham Respiratory Biomedical Research Unit.

Received 15 March 2011 Accepted 11 May 2011 Published Online First 15 June 2011

\section{ABSTRACT}

Idiopathic pulmonary fibrosis (IPF) is a chronic progressive disease of unknown aetiology. It has a very poor prognosis and no effective treatment. There are two major barriers to the development of novel treatments in IPF: an incomplete understanding of its pathogenesis and the fact that current models of the disease are poorly predictive of therapeutic response. Recent studies suggest an important role for the alveolar epithelium in the pathogenesis of IPF. However, practical limitations associated with isolation and culture of primary alveolar epithelial cells have hampered progress towards further elucidating their role in the pathogenesis of the disease or developing disease models that accurately reflect the epithelial contribution. The practical limitations of primary alveolar epithelial cell culture can be divided into technical, logistical and regulatory hurdles that need to be overcome to ensure rapid progress towards improved treatment for patients with IPF. To develop a strategy to facilitate alveolar epithelial cell harvest, retrieval and sharing between IPF research groups and to determine how these cells contribute to IPF, a workshop was organised to discuss the central issues surrounding epithelial cells in IPF (ECIPF). The central themes discussed in the workshop have been compiled as the proceedings of the ECIPF.

\section{INTRODUCTION}

Idiopathic pulmonary fibrosis (IPF) is a chronic progressive disease of unknown aetiology. The incidence of IPF has more than doubled in the UK in the last 15 years with approximately 5000 new cases each year. ${ }^{1}$ These incidence rates are higher than many cancers including renal, pelvic and haematological malignancies. Likewise, the prognosis of IPF is as grave as many tumours with 5 -year survival rates of $43 \%{ }^{2}$ and a median survival of 2.4 years. $^{3}$ No treatment has been found to be effective in altering the prognosis of the disease. ${ }^{4-6}$ Thus, IPF is a chronic, incurable and progressively fatal disease.

There are two major barriers to the development of novel effective therapies for IPF. First, there is incomplete understanding of the pathogenesis of the disease. The current paradigm suggests that, following repeated subclinical injury to the lung, there is epithelial damage with subsequent destruction of the alveolar-capillary basement membrane. This permits fibrogenic cell infiltration of the alveolar interstitium, with activation of fibroblasts leading to the generation of the highly contractile synthetic $\alpha$-smooth muscle actinpositive myofibroblast which is considered to be the key effector cell in pulmonary fibrosis. ${ }^{7}$ The alveolus is composed of alveolar type I and II (ATII) epithelial cells that adhere to the alveolar-capillary basement membrane. Following injury, normal wound healing requires that an intact epithelium be restored swiftly to re-establish barrier integrity and prevent excess mesenchymal activation and accumulation. This requires spatially and temporally coordinated responses leading to formation of a provisional matrix along which activated myofibroblasts migrate, promoting wound contraction. Epithelial cells migrate over the basal layer to regenerate the damaged area of lung before cellular debris and provisional matrix are remodelled and removed. In IPF the lung epithelium has several pathological features including hyperplasia of ATII, the presence of transitional epithelial cells, with areas of bronchiolisation and squamous metaplasia. $^{9-11}$ The integrity of the basement membrane is disrupted with hyperplastic ATII cell proliferation on an inappropriate extracellular matrix, with failure of restoration of normal alveolar structures. ${ }^{12}$ Furthermore, in lung fibrosis there is upregulation of epithelial-associated molecules involved in repair and development including integrins and components of the WNT signalling pathway. ${ }^{13-15}$ However, it is unknown whether these pathological changes of the epithelium are primary abnormalities or are a response to injury and whether they lead to the deposition of disordered matrix.

Second, current models of lung fibrosis do not reliably predict the clinical response to novel therapies. These model systems focus mainly on single-cell culture systems or animal models. Animal models have generated significant insights, especially when combined with data from human tissue. ${ }^{16-20}$ However, it has to be stated that all in vivo models rely, to some extent, on inducing injury in otherwise healthy lungs, whether by overexpressing transforming growth factor $\beta$ (TGF- $\beta$ ), instilling bleomycin, FITC, silica or vanadium, or exposing the animal to thoracic irradiation. Further understanding the role of epithelial cells in IPF is limited due to the poor availability of primary lung 
epithelial cells which are believed to play a crucial role in the disease process. Most of the work defining the pathogenesis of IPF has therefore been performed on epithelial cell lines derived from tumours or immortalised cells. The value of using malignant cells in such studies is unclear and alternative options include the use of rodent epithelial cells. There are certainly advantages to the use of rodent cells, including the logistical advantages of obtaining primary cells to order, the disease and treatment-free nature of the cells, the defined genetic background and the natural history of these cells. However, there are also limitations such as low yields of murine epithelilal cells, considerable variation among mouse strains and the relative lack of reagents for use in the rat to date.

Owing to the hurdles described, it is difficult to answer key questions such as whether enhanced injury promotes persisting epithelial damage or whether epithelial damage results from an abnormal epithelial response to injury. Similarly, we do not know if there is an intrinsic epithelial defect promoting fibrosis, or even whether targeting the epithelium will be a useful therapeutic strategy. Thus, the analysis and characterisation of the human alveolar epithelium, which in IPF is likely to have an intrinsic failure of wound repair, is indispensable and will undoubtedly shed further light on our understanding of IPF.

To overcome these barriers and to develop effective novel treatments, an improved supply of primary diseased and control alveolar lung epithelial cells is required. With well-phenotyped well-characterised primary human alveolar epithelial cells, meaningful comparative biology experiments can be performed. Furthermore, such cells could be used to develop 2D and 3D in vitro systems that may better predict the therapeutic response of IPF to novel treatments. However, to develop a usable supply of diseased primary epithelial cells, there are a number of hurdles that need to be overcome including biological, technical, logistical, ethical and regulatory barriers. All of these hurdles will require a nationally-or even internationally-coordinated approach to cell harvesting. A workshop on lung epithelial biology was therefore held on 15 October 2010 to determine a consensus approach to studying, harvesting and distributing primary alveolar epithelial cells throughout the UK which, in turn, could be used internationally.

\section{EPITHELIAL CELL BIOLOGY IN IPF}

The role of the alveolar epithelium in IPF is poorly understood due, in large part, to technical limitations in obtaining primary alveolar epithelial cells from patients with lung fibrosis. At present many studies use cell lines and surrogates such as A549 adenocarcinoma cells to generate and test hypotheses relating to the role of alveolar epithelial cells in IPF. ${ }^{21}$ Similarly, many groups use commercial sources of airway epithelial cells or rodent alveolar epithelial cells to investigate normal lung epithelial cell biology. Given the absence of data defining what constitutes a 'fibrotic' epithelial cell, it is important not to be too dogmatic about the initial approaches to studying IPF-related epithelial cell biology. While the cell lines may be suitable for initial exploratory IPF studies, data derived from such cells must acknowledge the limitations associated with these tools (eg, the clonal disruption of TGF- $\beta$ signalling pathways in tumour cells). Replication of key findings in primary cells must always be established before these data can be considered representative. A further challenge for researchers is the fact that there are no lineage tracing experiments that can conclude, with certainty, the origin of the hyperplastic epithelial cells that are characteristic of fibrotic lung. There are sufficient data demonstrating that both the large and small airways are abnormal in IPF to support the use of epithelial cells derived from the distal airway in initial hypothesis-generating experiments. ${ }^{22-25}$ While the use of such distal airway epithelial cells might be reasonable for studying generic lung epithelial pathways, it is probably not appropriate to use these cells as controls for comparative biology experiments with diseased ATII cells from IPF lungs.

The major challenges of using primary ATII cells relate to viability and fragility (they rarely survive freezing), limited replicative capacity when cultured, purity (lack of consistent markers and mesenchymal cell 'contamination' in disease states) and their tendency to acquire features of type I alveolar cells when cultured. ${ }^{26}$ How this might affect the key pathological pathways in IPF is unknown, but systematic phenotyping of epithelial cells from all regions of the lung and from freshly isolated lung epithelial cells prior to culture would help answer this fundamental question. As with all cell culture systems, tissue culture artefact is also a concern, but this may be minimised by culturing primary cells on Matrigel, in 2D or 3D coculture systems, culturing cells at the air-liquid interface and limiting the time in in vitro cell culture to ensure study of phenotypically relevant cells, but substrate-specific phenotypes are always likely to occur. ${ }^{27}$ Similarly, it is important to validate data obtained from mechanistic cell culture experiments to demonstrate that cell culture data may be representative of the disease. Techniques such as laser capture microdissection and immunohistochemistry can be used to augment in vitro data and overcome some cell culture limitations, but such studies are hampered by the ability to obtain appropriate control tissue for laser capture studies and the observational subjective nature of immunohistochemistry.

\section{OBTAINING LUNG EPITHELIAL CELLS FROM FIBROTIC LUNG TISSUE}

Currently there are three potential sources of lung tissue for the investigation of IPF: spare tissue from diagnostic clinical samples obtained from video-assisted thoracoscopic surgery (VATS) lung biopsies, lung from postmortem examination or explanted tissue following lung transplant surgery. There are significant drawbacks with each source.

VATS biopsies are usually performed when the diagnosis of IPF is unclear and in a younger population with a higher likelihood of having a diagnosis other than IPF. Furthermore, the yield of cells obtained from the 'spare' tissue is insufficient for meaningful studies. To obtain enough epithelial cells for in vitro culture experiments, a whole lobe needs to be processed. Explanted tissue is therefore necessary, but this can only be obtained from people with advanced fibrotic lung that yields fewer epithelial cells. Furthermore, there is concern that processes active in end-stage architecturally-remodelled fibrotic lung might not represent the pathobiology of early disease and may no longer be amenable to therapeutic manipulation.

The isolation of rodent type II cells was first described in 1974 by Kikkawa and Yoneda, ${ }^{28}$ and the protocol has since been adapted to isolate type II cells from a number of species including rodents, rabbits and humans. ${ }^{29}$ They all involve proteolytic (elastase, dispase and/or trypsin) digestion and many utilise density gradient separation and negative selection. Robinson et al were the first to isolate human type II cells in 1984 using a similar protocol. ${ }^{30}$ In normal human lung this approach can yield at least $1 \times 10^{6}$ cells/g of lung tissue, which are $95 \%$ pure ATII cells. ${ }^{31} 32$ Modifications of this method have been described to yield higher purities (up to 98\%) of human ATII cells using different enzymes and positive selection by flow cytometry $^{27}$ antibody-coated magnetic beads ${ }^{33}$ or differential 
adherence. ${ }^{34}$ The cells should be characterised by at least two epithelial markers, including $\mathrm{Sp}-\mathrm{C}$ and E-cadherin, to determine cell purity. Cells obtained from fibrotic lung using the latter protocol, however, are often contaminated, with only approximately $80 \%$ exhibiting classic ATII cell characteristics. ${ }^{35}$ Whether this is contamination with fibroblasts characteristic of IPF or represents nascent epithelial-to-mesenchymal transition remains to be determined. Flow Activated Cell Sorting (FACS) can be used to increase the purity of fibrotic epithelial cells, but at a vastly reduced yield (2-8 million/right middle lobe vs 160 million/right middle lobe). Furthermore, whether FACS leads to loss of the more diseased epithelial cells remains a concern. Finally, alveolar epithelial cell viability is dramatically reduced following freezing, thus making long-term storage of these cells impossible. Transportation and transfer of the cells between laboratories is therefore more challenging than with many other cell types.

LOGISTICS OF PRIMARY ALVEOLAR EPITHELIAL CELL BIOLOGY To study primary alveolar epithelial cells in IPF, a whole lobe should be digested and the cells harvested within $48 \mathrm{~h}$ of removal from the patient. Ideally, experiments should be performed on the cells within 7 days of harvest in order to preserve their pathological phenotype and limit change in culture. The whole middle lobe could be obtained from postmortem specimens harvested rapidly following death, ${ }^{36}$ but requires ante mortem identification and consent as well as rapid mobilisation of pathology departments. Practically, in the current UK environment, this could only be realistically considered for patients who die in hospital during office hours.

The most reliable source of IPF epithelial cells is therefore from explanted lungs harvested at the time of lung transplantation. However, there are only five lung transplant centres in the UK and only a small number of transplanted patients have IPF. Indeed, in 2008 only 157 patients with IPF received a lung transplant in the whole of the EU (population 500 million) compared with 516 in the USA (population 300 million). Furthermore, not all UK lung transplant centres have IPF research programmes and many IPF researchers do not work in transplant centres, so there is considerable wastage of potential research tissue. These limitations are further exacerbated by the challenging nature of harvesting diseased primary cells. Therefore, even where IPF researchers operate in transplant centres, explanted disease tissue will be wasted if the researchers cannot experiment on them immediately.

It is abundantly clear that explanted IPF tissue is a highly valuable research tool and, as such, it should not be wasted. However, at present in the UK and, to a large extent, within the $\mathrm{EU}$, systems are not in place to maximise explanted tissue retrieval. Crucially, successful epithelial cell harvest can occur up to $48 \mathrm{~h}$ after the lung has been removed from the patient if the lung is stored at $4^{\circ} \mathrm{C}$. Thus, the opportunity exists to develop a system that is responsive to the needs of the organ retrieval teams and researchers, permitting epithelial biology experiments throughout the UK. However, it will require a coordinated national approach to be successful.

\section{GOVERNANCE AND REGULATION}

The Human Tissue Act 2004 (HTA) laid down a framework for tissue storage and transfer, and it has placed consent firmly at the centre of all tissue-focused research. It also provided definitions and codes of practice to which all researchers must adhere. Since the Act became active on 1 September 2006 there has been a marked increase in procedural bureaucracy and not a little confusion. However, it has led to an improvement in archiving and curating tissue samples throughout the UK which, in turn, encourages and facilitates tissue sharing. The HTA has created an environment whereby organisations and institutions are looking to improve their regulatory and governance frameworks in a coordinated fashion owing to the nationwide implementation of the Act (with the exception of Scotland). Now is therefore the time to ensure that generic consent, tissue transfer agreements, research ethics approval as well as the standardised operating procedures for clinical phenotyping, tissue retrieval, harvest and storage are coordinated around UK centres to facilitate nationwide distribution of explanted diseased lung tissues.

\section{CONCLUSION}

Given the absence of a clear understanding of the pathogenesis of IPF, the lack of primary cells for comparative biology experiments and the disappointing failure to translate experimental data into viable treatments, the slow progress in developing therapies for treating IPF is hardly surprising. If novel effective treatments are to be developed, improving the tools to study the disease is a necessity. There is therefore an urgent need to develop mechanisms for harvesting and distributing primary epithelial cells from patients with IPF and controls.

Human tissue is an altruistic gift from patients to the research community, given in the hope that others may benefit from the research performed on their tissues. Thus, diseased as well as control tissue samples are an incredibly valuable resource because of the information that can be gained from their study and also because of the circumstances of their generation. Because of the scarcity of the tissue and its processing limitations, this value is amplified in IPF. It is therefore crucial that diseased lung tissue is not wasted.

To ensure maximal benefit from explanted disease tissue, it is essential that a network is established that is responsive to organ retrieval and researchers' requirements, thus enabling tissue to be obtained when available and distributed where it can be productively used at any given time. The basic requirements of this responsive network will include generic consent, biobanking facilities, core technical services, agreed standardised operating procedures, agreed access and governance procedures and logistical strategies. This will require a significant investment of time and resources, but there is no doubting the value of such a system-or the collective will-to implement such a process.

\section{Author affiliations}

${ }^{1}$ Respiratory Biomedical Research Unit, University of Nottingham, Nottingham, UK ${ }^{2}$ Respiratory Therapy Area, GlaxoSmithKline, Stevenage, UK

${ }^{3}$ Division of Pulmonary and Critical Care Medicine, Department of Medicine, Will Rogers Institute, Pulmonary Research Center, Keck School of Medicine, University of Southern California, Los Angeles, California, USA

${ }^{4}$ Department of Infection, Immunity and Inflammation, Institute for Lung Health, University of Leicester, Leicester, UK

${ }^{5}$ Trinity College Dublin, School of Pharmacy and Pharmaceutical Sciences, Dublin, Ireland

${ }^{6}$ Institute of Cellular Medicine, University of Newcastle, Newcastle Upon Tyne, UK

${ }^{7}$ Centre of Inflammation Research, University of Edinburgh, Edinburgh, UK

${ }^{8}$ Comprehensive Pneumology Center, Ludwig-Maximilians-University, University

Hospital Grosshadern, Helmholtz Zentrum München, Munich, Germany

${ }^{9}$ National Heart and Lung Institute, Imperial College London, London, UK

${ }^{10}$ Centre for Respiratory Research, University College London, Rayne Institute, London, UK

${ }^{11}$ Academic Respiratory Unit, University of Bristol, Southmead Hospital, Bristol, UK

${ }^{12}$ Division of Respiratory Medicine, University of Cambridge, School of Clinical

Medicine, Addenbrooke's and Papworth Hospitals, Cambridge, UK

${ }^{13}$ Lung Cell Biology, National Heart and Lung Institute, Imperial College, London, UK

${ }^{14}$ School of Clinical and Experimental Medicine, College of Health and Dental Sciences University of Birmingham, Birmingham, UK 
${ }^{15}$ Division of Pulmonary and Critical Care, University of California, San Francisco, California, USA

Funding The Workshop was part funded by the Nottingham Respiratory Biomedical Research Unit and GlaxoSmithKline.

Competing interests $A B, Z B, P B, C E, N H, M K, A M, T T, D T$ and $P W$ have no competing interests. GJ has received consultancy income from GlaxoSmithKline within the last 3 years and holds an MRC Industry Collaboration Award with GlaxoSmithKline. $\mathrm{AF}$ receives research funding from GlaxoSmithKline, Medlmmune and Chiesi. SJ has received consultancy income from GlaxoSmithKline and Novartis within the last 3 years. He holds a BBSRC Industry Collaboration Award with GlaxoSmithKline, an MRC CASE award with Mologic and has a research agreement with Mondobiotec. TM has received consultancy fees from Actelion, Boehringer Ingelheim, GlaxoSmithKline and Phillips Respironics within the last three years. He holds an unrestricted academic industry research grant from GlaxoSmithKline. HP has received consultancy income from GlaxoSmithKline within the last 3 years. CS has received consultancy income from GlaxoSmithKline within the last 3 years and holds a BBSRC Industrial CASE Award in collaboration with GlaxoSmithKline.

Contributors All contributors contributed to the writing of this manuscript.

Provenance and peer review Not commissioned; externally peer reviewed.

\section{REFERENCES}

1. Navaratnam V, Fleming KM, West J, et al. The rising incidence of IPF in the UK Thorax 2011:66:462-7.

2. Gribbin J, Hubbard RB, Le Jeune I, et al. Incidence and mortality of idiopathic pulmonary fibrosis and sarcoidosis in the UK. Thorax 2006;61:980-5.

3. Rudd RM, Prescott RJ, Chalmers JC, et al; Fibrosing Alveolitis Subcommittee of the Research Committee of the British Thoracic Society. British Thoracic Society study on cryptogenic fibrosing alveolitis: response to treatment and survival. Thorax 2007;62:62-6.

4. Demedts M, Behr J, Buhl R, et al. High-dose acetylcysteine in idiopathic pulmonary fibrosis. N Engl J Med 2005;353:2229-42.

5. Taniguchi H, Ebina M, Kondoh $\mathrm{Y}$, et al. Pirfenidone in idiopathic pulmonary fibrosis. Eur Respir J 2010;35:821-9.

6. Datta A, Scotton CJ, Chambers RC. Novel therapeutic approaches for pulmonary fibrosis. Br J Pharmacol 2011;163:141-72.

7. Eickelberg $\mathbf{0}$, Laurent GJ. The quest for the initial lesion in idiopathic pulmonary fibrosis: gene expression differences in IPF fibroblasts. Am J Respir Cell Mol Biol 2010;42:1-2.

8. Strieter RM, Mehrad B. New mechanisms of pulmonary fibrosis. Chest 2009:136:1364-70.

9. Kasper $\mathbf{M}$, Haroske G. Alterations in the alveolar epithelium after injury leading to pulmonary fibrosis. Histol Histopathol 1996:11:463-83.

10. Kawanami 0, Ferrans VJ, Fulmer JD, et al. Nuclear inclusions in alveolar epithelium of patients with fibrotic lung disorders. Am J Pathol 1979;94:301-22.

11. Kawanami 0, Ferrans VJ, Crystal RG. Structure of alveolar epithelial cells in patients with fibrotic lung disorders. Lab Invest 1982;46:39-53.

12. Basset $\mathbf{F}$, Ferrans VJ, Soler $P$, et al. Intraluminal fibrosis in interstitial lung disorders. Am J Pathol 1986:122:443-61.

13. Coward WR, Saini G, Jenkins G. The pathogenesis of idiopathic pulmonary fibrosis Ther Adv Respir Dis 2010:4:367-88.

14. Königshoff $\mathbf{M}$, Eickelberg 0 . WNT signaling in lung disease: a failure or a regeneration signal? Am J Respir Cell Mol Biol 2010;42:21-31.
15. Margadant C, Sonnenberg A. Integrin-TGF-beta crosstalk in fibrosis, cancer and wound healing. EMBO Rep 2010;11:97-105.

16. Xu MY, Porte J, Knox AJ, et al. Lysophosphatidic acid induces alphavbeta6 integrinmediated TGF-beta activation via the LPA2 receptor and the small $\mathrm{G}$ protein $\mathrm{G}$ alpha (q). Am J Pathol 2009;174:1264-79.

17. Scotton CJ, Krupiczojc MA, Königshoff $M$, et al. Increased local expression of coagulation factor $\mathrm{X}$ contributes to the fibrotic response in human and murine lung injury. J Clin Invest 2009;119:2550-63.

18. Königshoff $\mathbf{M}$, Kramer M, Balsara N, et al. WNT1-inducible signaling protein-1 mediates pulmonary fibrosis in mice and is upregulated in humans with idiopathic pulmonary fibrosis. J Clin Invest 2009;119:772-87.

19. Liu G, Friggeri $A$, Yang $Y$, et al. miR-21 mediates fibrogenic activation of pulmonary fibroblasts and lung fibrosis. J Exp Med 2010;207:1589-97.

20. Zuo F, Kaminski N, Eugui E, et al. Gene expression analysis reveals matrilysin as a key regulator of pulmonary fibrosis in mice and humans. Proc Natl Acad Sci U S A 2002;99:6292-7.

21. Buckley ST, Medina C, Ehrhardt C. Differential susceptibility to epithelial-mesenchyma transition (EMT) of alveolar, bronchial and intestinal epithelial cells in vitro and the effect of angiotensin II receptor inhibition. Cell Tissue Res 2010;342:39-51.

22. Shaw RJ, Djukanovic R, Tashkin DP, et al. The role of small airways in lung disease. Respir Med 2002;96:67-80.

23. Tiitto LH, Peltoniemi MJ, Kaarteenaho-Wiik RL, et al. Cell-specific regulation of gamma-glutamylcysteine synthetase in human interstitial lung diseases. Hum Pathol 2004;35:832-9.

24. Birring SS, Parker D, McKenna S, et al. Sputum eosinophilia in idiopathic pulmonary fibrosis. Inflamm Res 2005:54:51-6.

25. Seibold MA, Wise AL, Speer MC, et al. A common MUC5B promoter polymorphism and pulmonary fibrosis. N Engl J Med 2011:364:1503-12.

26. Demling N, Ehrhardt C, Kasper M, et al. Promotion of cell adherence and spreading a novel function of RAGE, the highly selective differentiation marker of human alveola epithelial type I cells. Cell Tissue Res 2006:323:475-88.

27. Marmai C, Sutherland RE, Kim KK, et al. Alveolar epithelial cells express mesenchymal proteins in patients with idiopathic pulmonary fibrosis. Am J Physiol Lung Cell Mol Physiol 2011. [Epub ahead of print] doi:10.1152/ajplung.00212.2010.

28. Kikkawa Y, Yoneda K. The type II epithelial cell of the lung. I. Method of isolation. Lab Invest 1974;30:76-84.

29. Dobbs LG. Isolation and culture of alveolar type II cells. Am J Physiol 1990;258 L134-47.

30. Robinson PC, Voelker DR, Mason RJ, Isolation and culture of human alveolar type II epithelial cells. Characterization of their phospholipid secretion. Am Rev Respir Dis 1984; 130:1156-60

31. Bingle L, Bull TB, Fox B, et al. Type II pneumocytes in mixed cell culture of human lung: a light and electron microscopic study. Environ Health Perspect 1990;85:71-80.

32. Witherden IR, Vanden Bon EJ, Goldstraw P, et al. Primary human alveolar type II epithelial cell chemokine release: effects of cigarette smoke and neutrophil elastase. Am J Respir Cell Mol Biol 2004;30:500-9.

33. Ehrhardt C, Kim KJ, Lehr CM. Isolation and culture of human alveolar epithelial cells Methods Mol Med 2005;107:207-16.

34. Witherden IR, Tetley TD. Isolation and culture of human alveolar type II pneumocytes. In: Rogers DF, Donnelly LE, eds. Human Airway Inflammation: Sampling Techniques and Analytical Protocols. Totowa, NJ: Humana Press Inc, 2001:137-41.

35. Maher TM, Evans IC, Bottoms SE, et al. Diminished prostaglandin E2 contributes to the apoptosis paradox in idiopathic pulmonary fibrosis. Am J Respir Crit Care Med 2010;182:73-82

36. Lindell KO, Erlen JA, Kaminski N. Lessons from our patients: development of a warm autopsy program. PLoS Med 2006;3:e234.

\section{Thorax Online Archive}

Visit our Online Archive - available back to 1946. Subscribers may access the entire archive freely. Non-subscribers have free access to all articles prior to 2006. A simple one-time registration is required that grants access to all the free archive content, across all of our specialist titles. To view or to register visit thorax.bmj.com. 